\title{
The myenteric plexus in drug-induced neuropathy
}

\author{
BARBARA SMITH \\ From the Department of Pathology, St. Bartholomew's Hospital, London
}

A number of drugs which are in use today produce a peripheral neuropathy as a toxic side-effect. The symptoms are usually confined to the peripheral nervous system, mainly the sensory-autonomic, and the central nervous system is unaffected. This could be due either to the fact that the substances in question do not cross the blood-brain barrier or to the fact that the cell affected is the Schwann cell only or in addition to the ganglion cell. The blood-brain barrier is certainly an important protection and it might not be possible to use a number of drugs, particularly cytotoxic ones, if they were not kept out of the brain. The main neurones which are outside the blood-brain barrier are those in the posterior root ganglia, the sympathetic ganglia, and the peripheral autonomic plexuses. Comparatively little morbid anatomy or experimental pathology has been done on drug-induced neuropathy, and the object of this study is to show that damage to the myenteric plexus in the large intestine is easy to produce and easy to demonstrate. It thus provides a means of assessing neurotoxicity in known and unknown substances.

\section{MATERIAL AND METHODS}

Forty-five mice, weighing 20-25 g., of three different strains were used, T.O., C.F.W., and Porton. There was some strain difference in the susceptibility of these animals, the last being the most sensitive, although lesions were produced in all. The drugs used were vinblastine sulphate, mepacrine methanesulphonate, and isonicotinic acid hydrazide (I.N.H.). Eighteen animals were given $0.005 \mathrm{mg}$. or $0.05 \mathrm{mg}$. of vinblastine sulphate intraperitoneally daily, the number of doses varying from three to six; 18 were given mepacrine methanesulphonate, $3 \mathrm{mg}$. intraperitoneally for five days, and nine were given I.N.H., $5 \mathrm{mg}$. intraperitoneally twice weekly for between five and 20 doses. The animals were killed two to three days after the last dose to assess the acute damage and three weeks to three months later to assess recovery. In addition six acute experiments were done in which mepacrine methanesulphonate was injected, either $10 \mathrm{mg}$. intraperitoneally or $2 \mathrm{mg}$. intravenously. The animals were killed 20 minutes later and the gut wall examined under the fluorescent microscope.

Kidney, liver, heart, intestine, brain, spinal cord, and posterior root ganglia were examined in paraffin section.
In four animals who had received 20 doses of I.N.H. the posterior tibial nerves were stained with osmium tetroxide and teased into single fibres. The skeletal muscle was examined by silver impregnation. The myenteric plexus studies were done on the distal portion of the large intestine. The gut was opened immediately and the mucosa removed; the muscle coats were laid flat on a slide and stained by the Schofield (1960) technique.

\section{RESULTS}

Animals given vinblastine or mepacrine sometimes developed abdominal distension three to seven days after the first dose. This was not so in every case and was more marked in the Porton strain than others. It was mainly due to dilatation of the proximal colon and distal ileum, the distal colon remaining of normal size. There was often no solid faeces in the large intestine either in the proximal dilated part or in the distal contracted part; it contained a watery fluid. When the gut was pinched it was unresponsive and this was true of all animals, not only the ones with dilated intestines. Animals given the larger dose of vinblastine did not survive more than 10 days and the survival studies were done on animals receiving the smaller dose. Animals given I.N.H. showed no microscopic evidence of gut abnormality and remained in good health throughout.

With all drugs used the kidney, liver, heart, intestine, brain, and spinal cord showed no significant histological abnormality. The posterior root ganglia showed varying degrees of neuronal damage which was worse in the animals treated with vinblastine. Some cells were shrunken and stained reddish instead of blue. In other neurones the R.N.A. was found at the periphery of the cell (Fig. 1). Vinblastine produced some damage to skeletal muscle fibres, producing swollen hyaline fibres with occasional necrosis. The changes were less severe than have been reported by others (Slotwiner, Song, and Anderson, 1966) but this is probably due to differences in dosage and in the time at which the sample was obtained. The innervation of the extrafusal fibres and of the spindles was normal.

In the normal mouse silver impregnation shows the myenteric plexus to consist of a geometric net- 


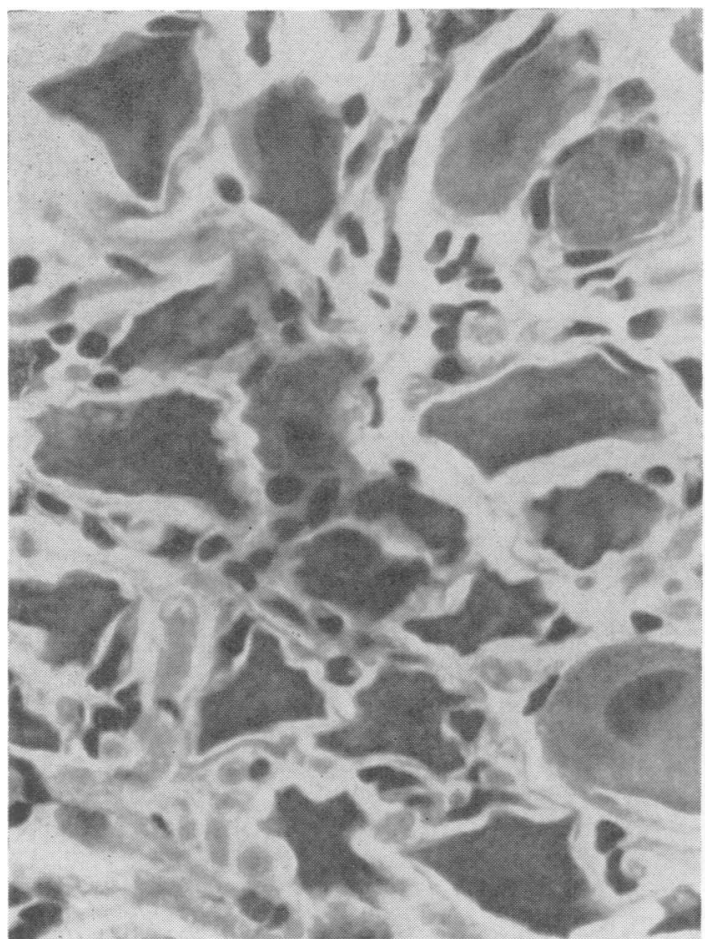

FIG. 1

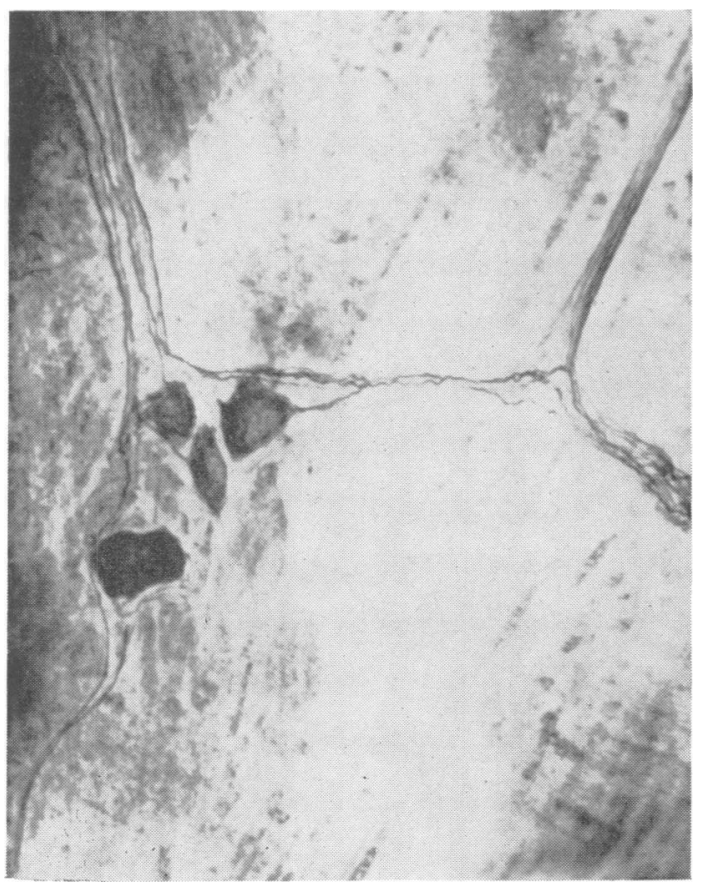

FIG. 3

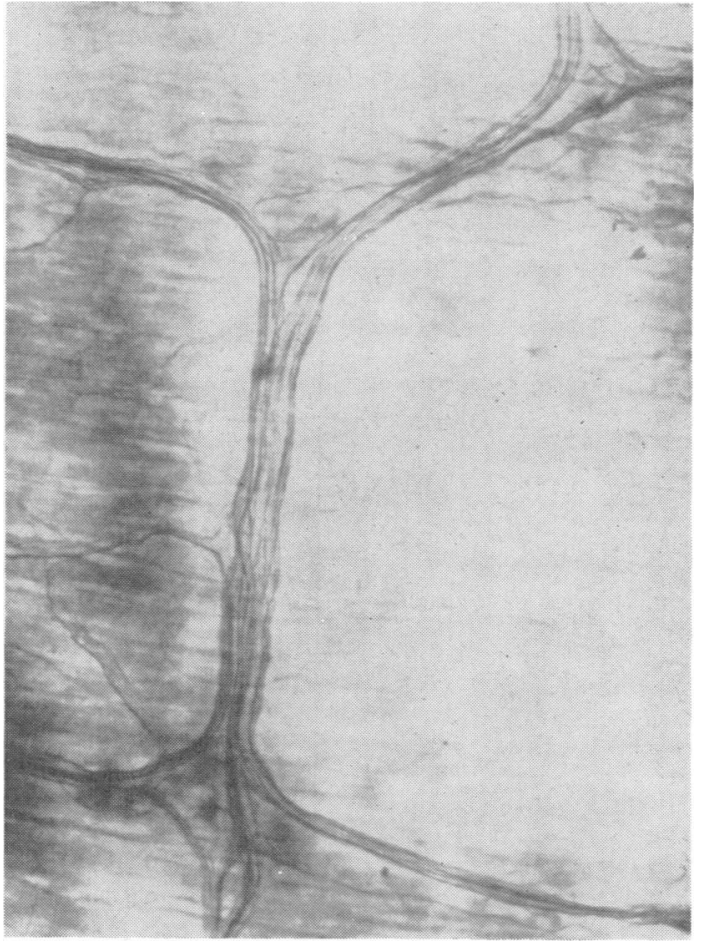

FIG. 2

FIG. 1. A posterior root ganglion from a mouse which had received a total of a $100 \mathrm{mg}$. of I.N.H. intraperitoneally. Some neurones are shrunken and the R.N.A. is displaced periphally. Haematoxylin and eosin $\times 500$.

FIG. 2. The myenteric plexus of a normal mouse. It consists of groups of axons running together in a somewhat geometrical arrangement with single fibres branching off to supply the two muscle coats. The neurones are mainly situated in the angles but a few along the trunks. In the normal they are not argentophilic and do not stain. Schofield $\times 300$.

FIG. 3. The myenteric plexus from a mouse killed the day after the third daily dose of $0.005 \mathrm{mg}$. of vinblastine. The neurones are argentophilic and the axons are beginning to show some irregular swelling. Schofield $\times 300$. 


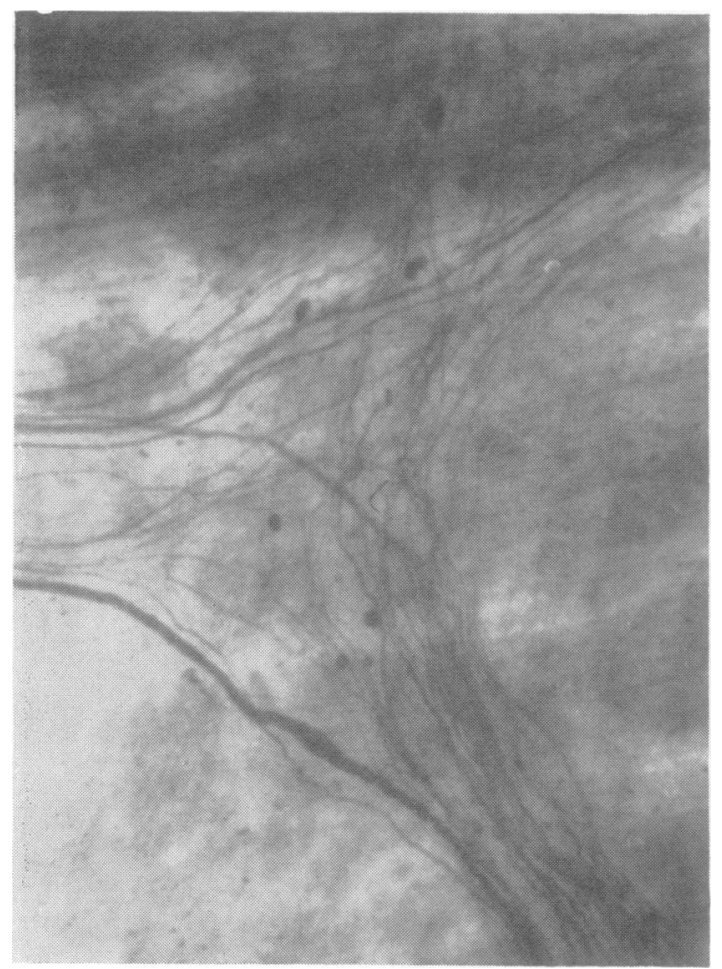

FIG. 4

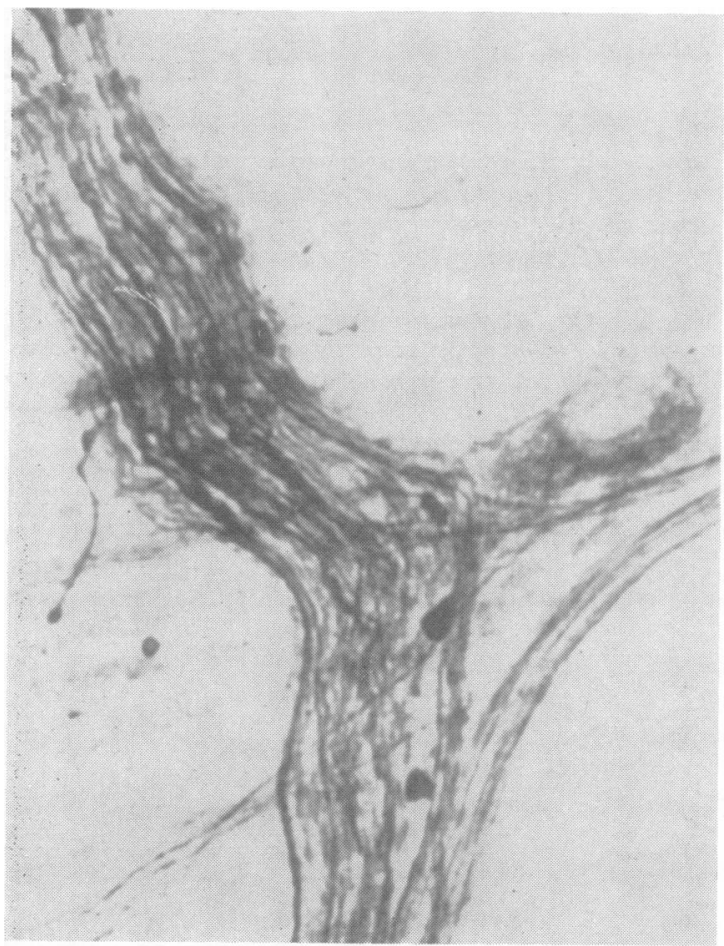

FIG. 6

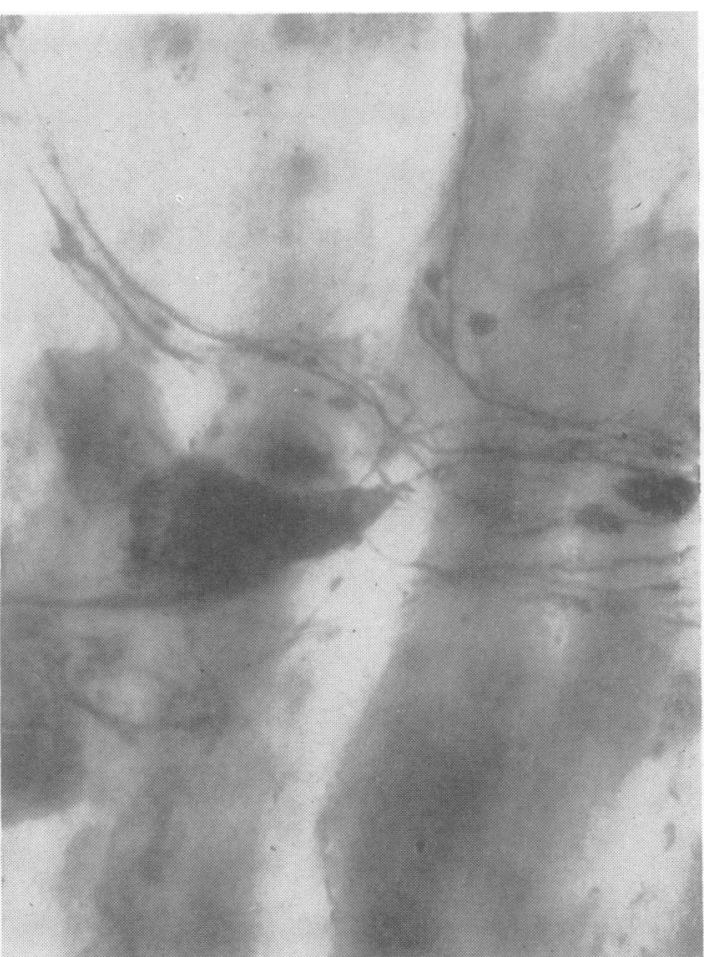

FIG. 5

FIG. 4. The myenteric plexus from a mouse killed three days after the last of five daily doses of $3 \mathrm{mg}$. of mepacrine methanesulphonate. There are a number of axon swellings in the ganglion. The thick fibre on the left is an extrinsic one. Schofield $\times 500$.

FIG. 5. The myenteric plexus from a mouse which had received four daily doses of $0.05 \mathrm{mg}$. of vinblastine sulphate and was killed the following day. The abdomen was grossly distended due to dilatation of the proximal colon and distal ileum. The ganglion cells have become argentophilic and the axons are breaking up with retraction balls. Schofield $\times 500$.

FIG. 6. The myenteric plexus from a mouse which had received $5 \mathrm{mg}$. of I.N.H. twice weekly for four weeks. A number of axon swellings are seen. Schofield $\times 550$. 


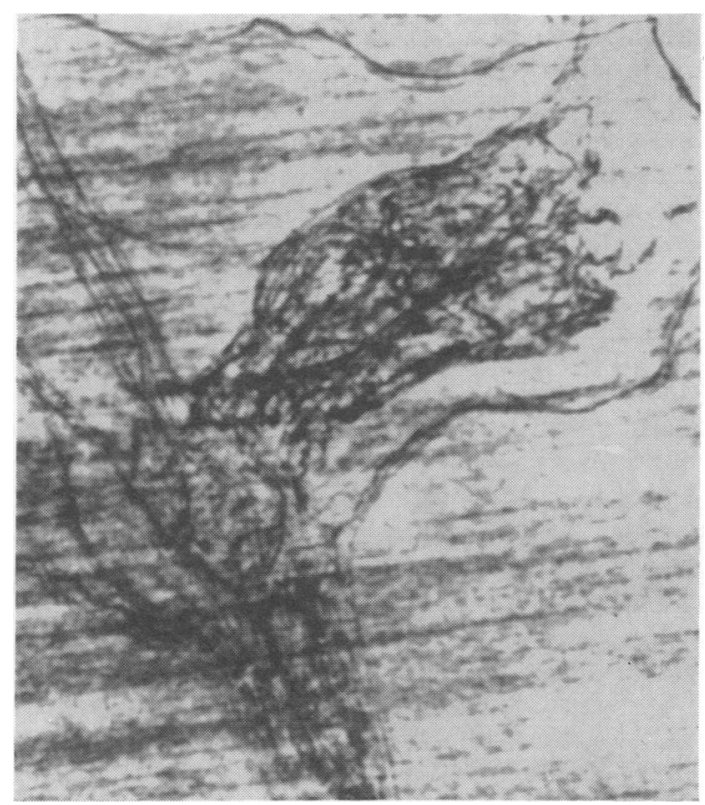

FIG. 7. The myenteric plexus from a mouse which had received $70 \mathrm{mg}$. of I.N.H. for seven weeks. The ganglion is replaced by an interlacing network of argentophil fibres. Schofield $\times 550$.

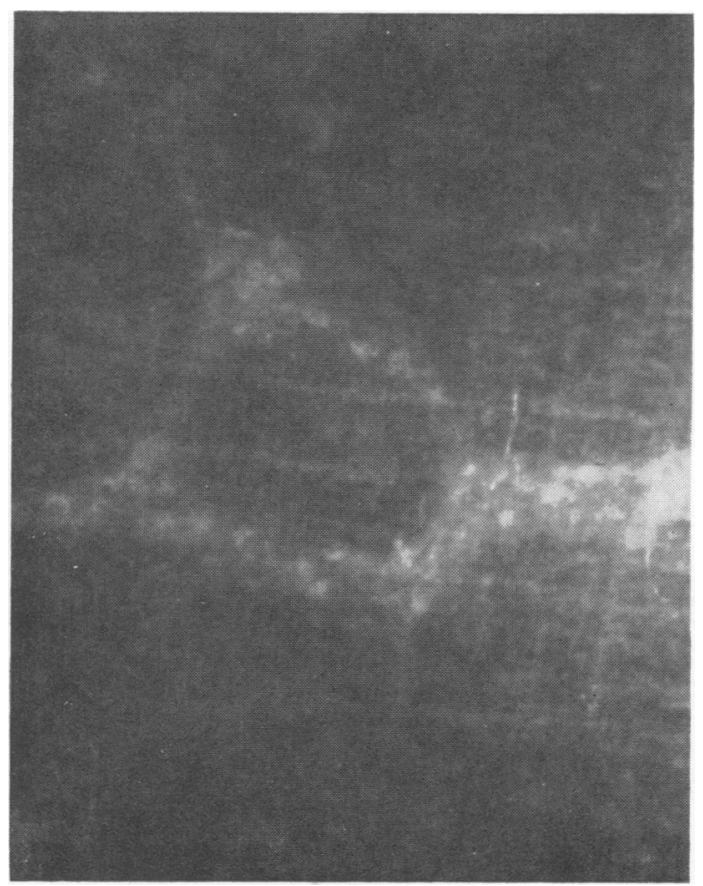

FIG. 8. The myenteric plexus from a mouse which had received $10 \mathrm{mg}$. of mepacrine mathanesulphonate 20 minutes previously. The section is viewed with ultraviolet light and the neurones are fluorescent. $\times 150$. work of nerve fibres usually running in groups of five or six; very often one is much thicker than the others and is an extrinsic fibre running in the plexus. The fibres are straight and uniform in diameter, and axonal swellings are extremely rare. In the mouse, although not in all other mammals, the majority of neurones are not argentophilic, so that only an occasional one is visible, the ganglia being shown as junctions of axons (Fig. 2). When the plexus is damaged, an early histological change is the development of neuronal argentophilia (Fig. 3). All the damage seen appeared to be related to the acuteness and severity of the lesion and the length of time it had been present, rather than to the particular drug. The changes were numerous axonal swellings, particularly in the neighbourhood of the ganglia (Figs. 4, 5, and 6). Later on these appeared also in the nerve trunks. In severely affected animals with dilated intestines disintegration of the plexus became very considerable. In animals given I.N.H., in addition to some damage to the plexus, the ganglia became replaced by a plexiform network of fibres (Fig. 7). This same network was seen in all the animals who had been poisoned and allowed to recover, and appears to be a change which occurs regularly but takes some time to produce. In the animals allowed to recover the other evidence of plexus damage had disappeared.

In the acute experiments, in which mepacrine methanesulphate was injected intravenously or intraperitoneally and the animals killed 20 minutes later, the gut was flabby and dilated and did not respond to pinching. The neurones of the plexus could be seen under the fluorescent microscope to contain the drug (Fig. 8). It was more obvious in those in which the drug was given intraperitoneally, both due to the locality of the substance in relation to the gut and to the fact that it was possible to give a much larger dose. It was, however, just visible when the drug was given intravenously.

\section{DISCUSSION}

Vinblastine sulphate is used in the treatment of malignant disease, particularly lymphomas. It is known to produce considerable dilatation of the gut in man. One patient was admitted to another hospital and the gut was found to be so distended that a laparotomy was performed (Bleehen and Jelliffe, 1965). Post-mortem examinations of patients being given this drug show myenteric plexus damage (personal observation). Like many other oncolytic drugs it probably interferes with nucleic acid metabolism, although the exact biochemistry is not known. It is, perhaps, not surprising that drugs which are given with the intention of disrupt- 
ing some aspect of nucleic acid synthesis should affect neurones which contain such large quantities of D.N.A. and R.N.A.

Mepacrine given intraperitoneally has been shown by Keeler, Richardson, and Watson (1966) to produce enteromegaly in rats. It was used in this study because it is sufficiently fluorescent to be shown within the neurones, thus demonstrating a specific affinity of the drug for these cells. It appears to have an affinity for nucleic acids, as does acridine orange, which is somewhat similar chemically. If given in very large doses it can be made to stain the D.N.A. too before the animal dies. The drug has no effect on colonic function when given by mouth. This is probably because it is absorbed relatively slowly and the toal plasma concentration never reaches the critical level necessary as it does if the drug is given parenterally. The mechanism of the antimalarial activity of mepacrine has not been elucidated and its neurotoxic effect remains obscure.

Isotinic acid hydrazide has been known to produce peripheral neuropathy in man and the experimental animal for a number of years. Klinghardt (1954) demonstrated demyelination in peripheral nerves in rats given the drug. In this study the amount of drug used was only about a third of that used by other investigators, and no detectable damage was produced to the sensorimotor nerves. This seems to show that the myenteric plexus is a more sensitive indicator of neurotoxicity than they are. I.N.H. is a substance which almost certainly does cross the blood-brain barrier and Cavanagh (1967) has shown axonal degeneration in anterior roots in rats. However, clinically the sensory-autonomic system is affected first and then only if the drug is then continued in large doses is motor loss apparent; when it occurs denervation atrophy can of course be demonstrated in skeletal muscle. However, the majority of drug neuropathies do not or cannot progress to motor nerve damage and it is useful to have a means of assessing lesions of the autonomic nervous system. The myenteric plexus can be used for this purpose.

\section{SUMMARY}

Three drugs-vinblastine sulphate, mepacrine methanesulphate, and isonicotonic acid hydrazidewere given intraperitoneally to mice. Functional abnormalities of the large gut were produced and histological changes seen in the myenteric plexus. As these changes can be readily recognized this technique could be used in assessing the neurotoxicity of drugs.

This work was supported by a grant from the Muscular Dystrophy Group of Great Britain. The photographs were taken by Mr. P. Crocker. The mepacrine methanesulphate was kindly supplied by May and Baker Ltd., and the vinblastine sulphate by Eli Lilly \& Co. Ltd.

\section{REFERENCES}

Bleehen, N. M., and Jelliffe, A. M. (1965). Vinblastine Sulphate in the treatment of malignant disease. Brit. J. Cancer, 19, 268-273.

Cavanagh, J. B. (1967). On the pattern of change in peripheral nerves produced by isoniazid intoxication in rats. J. Neurol. Neurosurg. Psychiat., 30, 26-33.

Keeler, R., Richardson, H., and Watson, A. J. (1966). Enteromegaly and steatorrhea in the rat following intraperitoneal quinacrine (atabrine). Lab. Invest., 15, 1253-1262.

Klinghardt, G. W. (1954). Experimentelle Nervenfaserschädigungen durch Isonicotinsäurehydrazid und ihre Bedeutung für die Klinik. Verh. Dtsch. Ges. inn. Med., 60, 764-768.

Schofield, G. C. (1960). Experimental studies on the innervation of the mucous membrane of the gut. Brain, 83, 490-514.

Slotwiner, P., Song, S. K., and Anderson, P. J. (1966). Spheromembranous degeneration of muscle induced by vincristine. Arch. Neurol. (Chic.), 15, 172-176. 